rate as a share of the economy (investment rate). They found that metal footprints follow the business cycle, and that they fall by a particularly large proportion during recessions. They also found a strong link with the investment rate. Every percentage-point increase in gross capital formation, as a share of gross domestic product, tends to increase a country's metal footprint by around $2 \%$. Countries that boost their spending on capital goods such as bridges, apartment buildings and machinery therefore typically have rising metal footprints. Aside from gross domestic product and the rate of gross capital formation, the authors did not find strong evidence that fluctuations in some other key variables, such as the industrial production share of the economy, have major short-term influences on countries' metal footprints.

It follows that China's move to a somewhat slower rate of economic growth, and its rebalancing towards a more consumptionled development model, released some of the pressure from global metal demand growth after 2011. This forms part of the explanation for lower metal prices relative to the highs they reached during the commodity boom. Metal prices have since rallied again throughout 2016 and 2017 (ref. ${ }^{6}$ ).
It also follows that the decline in the United States' metal footprint can be partly linked to a falling investment rate, the economic contraction of 2008-2009, and a general slowing in its rate of economic growth.

The world's growing metal footprint heightens the need for appropriate policies to mitigate the serious environmental impacts of the metal supply industry. These impacts include pollution of waterways, ecosystem loss and greenhouse gas emissions. Economists have long emphasized the need for taxes and charges to complement the other legal requirements imposed on industry operators. Environmental pricing schemes, including carbon taxes, would incentivize the economy to reorient itself towards low-impact extraction, processing and transportation processes. Other aspects of resource governance, for example ensuring appropriate collection of resource rents from mining projects and improved systems to encourage end-of-life recycling, are also pressing priorities in many countries.

The history of human development remains young, and the thirst for improving living standards is far from quenched. Looking forward, there are likely to be a number of growing sources of demand for both common and rare metals, including for technologies for a low-carbon energy system, such as solar panels, wind turbines and batteries ${ }^{7}$. The findings of Zheng et al. suggest that while some developing countries may show strong future growth in demand for metal-intensive products, this demand may well exhibit a high degree of short-term variability in response to prevailing economic conditions.

\section{Paul J. Burke}

Crawford School of Public Policy, Australian National University, Acton, Australian Capital Territory, Australia.

e-mail:paul.j.burke@anu.edu.au

Published online: 2 April 2018

https://doi.org/10.1038/s41561-018-0101-0

References

1. Zheng, X. et al. Nat. Geosci. https://doi.org/10.1038/s41561-0180091-y (2017).

2. Wackernagel, M. et al. Ecol. Econ. 3, 375-390 (1999).

3. Oita, A. et al. Nat. Geosci. 9, 111-115 (2016).

4. Hoekstra, A. Y. \& Mekonnen, M. M. Proc. Natl Acad. Sci. USA 109, 3232-3237 (2012).

5. Hertwich, E. G. \& Peters, G. P. Environ. Sci. Technol. 43, 6414 6420 (2009).

6. Commodity Markets Outlook (The World Bank, 2017).

7. Vidal, O., Goffé, B. \& Arndt, N. Nat. Geosci. 6, 894-896 (2013).

\title{
PETROLOGY
}

\section{Earthquake record in garnet}

The beauty of garnet has been appreciated since the Bronze Age, as demonstrated by its use as a gemstone. But its utility extends far beyond the decorative: garnet is widely used to determine the temperatures and pressures a rock has been exposed to during metamorphism. However, there is yet more to learn from these remarkable minerals.

Large, catastrophic earthquakes can occur in subduction zones. In this setting, the rocks undergo metamorphism at high pressures, but relatively low temperatures. As the seismic waves pass through, overpressure is released. After the earthquake, overpressure begins to develop again and garnet growth continues. These cycles of overpressure and dissipation can be recorded in garnets for individual earthquake events, note Daniel Viete and colleagues (Sci. Adv. http://doi.org/cmrt; 2018).

Akin to tree-rings as a store for a history of climate and environmental change, geochemical zonations in garnets lock in a record of earthquake-induced cycles of rising and falling pressure.

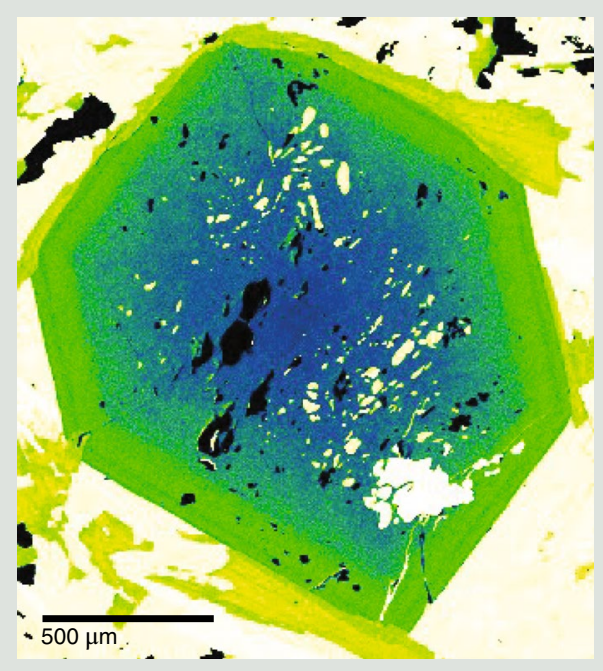

Credit: Figure reproduced from Viete et al. (Sci. Adv. http://doi.org/cmrt; 2018), AAAS.

Using a host of geochemical analyses and microspectroscopy, Viete and colleagues find that trapped within the major-element zoning of subduction-zone garnets from the Franciscan Complex, California, are geochemical indicators of four substantial pressure pulses, each of 100-350 MPa, within a geologically brief window of less than 300,000 years.

Our understanding of subductionzone earthquake recurrence rates and magnitudes is currently somewhat limited, to the past 2.5 million years or so of Earth's history, as we rely on the sedimentary record to identify the effects of subductionzone seismicity. The chemical zoning in garnets, here dating back at least 145 million years, may therefore allow the paleoseismic record to be extended much further back in time. These gemstones may therefore help reconstruct the magnitude and reoccurrence rate of ancient megathrust earthquakes and the evolution of stress within the crust.

\section{Rebecca Neely}

Published online: 4 April 2018

https://doi.org/10.1038/s41561-018-0106-8 